\title{
Brewers' Spent Grains: Drying Kinetics and Biodiesel Production
}

\author{
Elliot Mallen and Vesna Najdanovic-Visak ${ }^{*}$ \\ Engineering Department, Faculty of Science and Technology, Lancaster University, United \\ Kingdom \\ *corresponding author: Engineering Building, Lancaster University, Gillow Avenue, \\ Lancaster LA1 4YW, United Kingdom; Tel: +44 (0)1524 593 586; email: \\ v.najdanovic@lancaster.ac.uk
}

\begin{abstract}
Enormous amounts of brewers' spent grains (BSGs) per year are generated to produce bear worldwide. BSGs can be used as a carbon source, biofuel to generate energy and as a source of biogas. Typically, BSGs contain more than 60 mass $\%$ of water and, therefore, drying kinetics is a paramount for the development of any of these valorisation processes.

In this work, we reveal the main parameters and mechanism of drying kinetics of BSGs at isothermal conditions $\left(60^{\circ} \mathrm{C}-90^{\circ} \mathrm{C}\right)$, measured by thermogravimetric analysis. Diffusion coefficients ranged from $1.42 \times 10^{-9} \mathrm{~m}^{2} \mathrm{~s}^{-1}$ to $2.67 \times 10^{-9} \mathrm{~m}^{2} \mathrm{~s}^{-1}$ while the activation energy was $26.6 \mathrm{kJmol}^{-1}$.

Furthermore, for the first time, biodiesel production from BSGs is reported. We employed acid catalysed in situ transesterification process, at different catalyst concentrations, methanol to BSGs ratios, reaction time and temperature.
\end{abstract}

The outcomes of our study show promise for alternative valorisation of brewers' spent grains, an abundant waste spread around the world.

Keywords: Thermogravimetric analysis (TGA); In situ transesterification; Drying mechanisms; Reactive extraction. 


\section{Introduction}

In 2016, the global beer production was 1.96 billion hectolitres, up from 1.3 billion hectolitres in 1998 (Statista 2017). According to the Brewers of Europe report published in 2016, Europe is the second largest beer producer in the world after China, with over 6500 breweries producing over 383 million hectolitres of beer. Consumer spending in the European Union was over $€ 110$ billion in 2014 , which is predicted to increase in years to come. America is also capitalising on the economic incline of the beer industry providing over $\$ 55.7$ billion to the economy in 2014 and contributing to over 424,000 jobs (Watson, 2016). The beer production starts with malting process which involves few stages (cleaning, germination, drying and storing) to prepare grains for the brewing process. Malted grains are milled to enhance sugar recovery in the mashing process where the so-called saccharification takes place. This is a conversion of starches into sugars which are then fermented to produce beer in the following stage. The by-product of the mashing process is brewers' spent grains (BSGs) which accounts for $85 \%$ of the by-products produced by any brewery (Roberto et al., 2006). According to Thomas and Rahman, 2006, approximately $45 \mathrm{~kg}$ of BSGs are generated per 100 litres of produced beer, meaning that approximately 87 million tonnes of BSGs are generated to produce 193 billion litres of bear per year worldwide.

In the recent years, major research has been focused on BSGs utilization as a carbon source for bioethanol production, biofuel to generate heat and/or electricity and as a source of biogas. It was shown that biorefinery concept can be employed for the utilization of BSGs to produce xylitol, lactic acid, activated carbon and phenolic acids (Mussatto et al., 2013). Furthermore, integrated energy and chemical production was the most recommended path for the implementation. Recent studies have shown that BSGs can also be used as a feedstock for production of butanol (Plaza et al., 2017), hydrogen (Zhang and Zang, 2016) and carboxylic acid (Liang and Wan, 2015). 
According to the review of O'Brien et al., 2012, dry BSGs are composed of 14.2-26.7\% of proteins, $3.9-13.3 \%$ of lipids, $12.0-25.4 \%$ of cellulose, $21.8-40.2 \%$ of hemicellulose and 4.0-27.8\% of lignin. These high fibre and protein contents make BSGs an affective feed for animals. Animals benefit from the nitrogen content of the feed, providing excess of amino acids which leads to increased yields of milk in cows (Roberto et al., 2006).

BSGs has high moisture content, approximately 70\%, causing two issues (Lynch et al, 2016): 1) transport of wet BSGs can be costly which might limit the supply of cattle feed to local farmers only; 2) microbial growth and associated decomposition is enhanced by its high content in polysaccharide, proteins and moisture. Unfortunately, these issues impede the aforementioned utilizations of this enormous low-cost waste.

Drying pre-treatment is one of the most common methods to remove moisture from biomass. It is of utmost importance to determine the optimum drying conditions in order to minimize energy consumption and the cost of the drying. Despite this, to the best of our knowledge, drying kinetics for BSGs has not been reported in literature.

It is important to note that the oil content of BSGs ranges from $3.9 \%$ to $13.3 \%$ on dry bases [the same as above??] which is comparable with the oil content found in the other feedstocks such as $20 \%$ in Jatropha curcas (Sinha et al., 2015), 14\% in spent coffee grounds (Najdanovic-Visak et al., 2017) and other agricultural waste including seeds of tea, tobacco or tomato, linseed and bay laurel leaves (Rehan et al., 2017).

On the contrary to the traditional method comprising of oil extraction, solvent evaporation and chemical conversion of oils to biodiesel, in situ transesterification offer a one pot operation where extraction and transesterification occur simultaneously. Several studies have employed this method for various kinds of biomass such as algae (Kim et al., 2015, Haas and Wagner, 2011), rapeseed (Qian et al., 2013), Jatropha (Kasim and Harvey, 2011), spent 
coffee grounds (Park et al., 2006; Najdanovic-Visak et al., 2017), soy flakes (Haas et al., 2004), etc.

Therefore, the aim of this paper is to: (1) determine the drying kinetics of BSGs and calculate drying parameters at $60^{\circ} \mathrm{C}$ to $90^{\circ} \mathrm{C}$, using thermogravimetric analyser; 2) produce biodiesel from BSGs oils using acid catalysed in situ transesterification process under different concentrations of catalyst, distinct methanol to BSGs ratios, different reaction time and temperature.

\section{Materials and Methods}

\subsection{Materials}

The brewers' spent grains (BSGs) were supplied by the Bank's Brewery - Marston's PLC. BSGs were collected from the spent grain silo shortly after being removed from the mashing process.

All the chemicals used in experimental procedures were purchased from Sigma-Aldrich (UK) and used without further purification: anhydrous methanol (CAS67-56-1, $\geq 99.8 \%$ ), n-hexane (CAS110-54-3, $\geq 95 \%$ ), sulphuric acid (CAS7664-93-9, $\geq 97.5 \%$ ), sodium chloride

(CAS 7647-14-5, $\geq 99 \%$ ), diethyl ether (CAS60-29-7, $\geq 99 \%$ ), ethanol (CAS 64-17-5, $\geq$ 95\%), sodium hydroxide (CAS1310-73-2) and phenolphthalein (CAS77-09-8, $\geq 99 \%$ ).

\subsection{Moisture, oil content and acid value}

Collected BSGs were analysed for water, oil and acid content. The water content of BSGs was determined immediately after the collection, by measuring the mass before and after the drying in an oven at $80^{\circ} \mathrm{C}$, until no further changes in mass were observed. For this purpose, AT201 analytical balance (Mettler, UK) was used. The same procedure was repeated three times and the obtained average moisture content was within \pm 0.5 mass $\%$. 
n-Hexane was used to determine the oil content of the dried SCGs, by performing the Soxhlet extraction at its normal boiling point. Approximately $30 \mathrm{~g}$ of BSGs were used and the extraction was carried out for six hours. Hexane was subsequently evaporated in a rotary evaporator and the content of the extracted oil was determined gravimetrically using the analytical balance. Soxhlet extraction was repeated three times and obtained average oil content was within \pm 0.1 mass $\%$.

Samples of the extracted oils were further titrated by sodium hydroxide, to determine the oil's acid value by the standard AOCS method. The latter defines the acid value as mg of $\mathrm{KOH}$ used to neutralise one gram of oils. The titrations were repeated three times and the average standard error was less than $3 \%$.

\subsection{Drying kinetics}

The drying kinetics were obtained according to the previously reported method (Chen et al., 2013) at four temperatures $\left(60^{\circ} \mathrm{C}, 70^{\circ} \mathrm{C}, 80^{\circ} \mathrm{C}\right.$ and $\left.90^{\circ} \mathrm{C}\right)$, using a thermogravimetric analyser (NETZSCH, model STA $449 \mathrm{~F} 3$ ) and nitrogen as a carrier gas, flowing at $20 \mathrm{~mL} / \mathrm{min}$. In order to check if the mass and heat transfers inside the sample are negligible, the experiments were performed using various initial sample masses ranging from $10 \mathrm{mg}$ to $25 \mathrm{mg}$ (Yang et al., 2004) and no significant changes in drying kinetics were observed. Finally, $25 \mathrm{mg}$ sample was selected to be used in all the experiments. The TGA was run under Proteus ${ }^{\circledR}$ Software allowing automatic record of changes in mass. All the experiments were replicated three times at each temperature and averages of mass loss were used.

The moisture ratio $(M R)$ of BSGs can be determined by the following equation:

$$
M R=\frac{\left(M-M_{e}\right)}{\left(M_{0}-M_{e}\right)}
$$


where $M, M_{\mathrm{e}}$ and $M_{0}$ stand for the moisture content at time $t$, the equilibrium moisture content and the initial moisture content, respectively. The value of $M_{\mathrm{e}}$ was equivalent to the moisture content at the end of drying when the mass of sample became constant with time.

Drying curves (moisture ratio as a function of time) were fitted using regression analysis with four isothermal models (Ertekin and Firat, 2017): Page, Newton, Midilli-Kucuk and Logaritmic, as presented in Table 1. The discrepancies between the experimental and the values obtained from the models were evaluated from the coefficient of determination $\left(r^{2}\right)$ and the standard deviation $(S D)$ between the predicted and experimental values, given by:

$$
S D=\sqrt{\frac{\sum_{i=1}^{N}\left(M R_{\text {exp }}-M R_{\text {model }}\right)}{N-1}}
$$

where $M R_{\exp }, M R_{\text {model }}$ and $N$ are the experimental moisture ratio, calculated moisture ratio from the model and number of experimental points, respectively.

Fick's second law shown in equation (3) describes the mass-diffusion of water from biomass during its falling rate period - where transfer of moisture from the inner matrix of the grain to the outer surface becomes the limiting factor which reduces the drying rate (Barton, 1975).

$$
\frac{\partial M R}{\partial t}=\nabla\left[D_{e f f}(\nabla M R)\right]
$$

where $M R, t$ and $D_{\text {eff }}$ are moisture ratio, time and effective diffusivity, respectively. Assuming that i) the process took place under isothermal conditions, ii) the moisture transport was dominated by the internal diffusion, iii) there was a uniform initial moisture distribution, and iv) shrinkage was negligible (Chen et al., 2012), the solution to equation (3) is given as: 


$$
M R=\frac{8}{\pi^{2}} \sum_{n=0}^{\infty} \frac{1}{(2 n+1)^{2}} \exp \left(-\frac{(2 n+1)^{2} \pi^{2} D_{e f f} t}{4 L^{2}}\right)
$$

where $L$ is half of the sample thickness (m). Equation can be further simplified into:

$$
\ln M R=\ln \left(\frac{8}{\pi^{2}}\right)-\left(\frac{\pi^{2} D_{e f f}}{4 L^{2}} t\right)
$$

The natural logarithm of $M R$ was plotted against time to gather the effective diffusivity for the four tested isotherms. Activation energy $\left(E_{a}\right)$ was calculated using the Arrhenius relationship:

$$
D e f f=D_{o} \exp \left(-\frac{E_{a}}{R T}\right)
$$

where $D_{o}, T$ and $R$ are the pre-exponential factor, temperature and the ideal gas constant, respectively. The activation energy was calculated by plotting $\ln \left(D_{\text {eff }}\right)$ as a function of the reciprocal of the temperature which gave a straight line with the slope equal to $-E_{a} / R$

\subsection{In situ transesterification}

Desired amounts of sulphuric acid and methanol were mixed in a 500-mL 3-neck round bottom flask fitted with a condenser to avoid evaporation. The flask was immersed in a temperature controlled water bath $( \pm 1 \mathrm{~K})$ and heated to a desired temperature. Next, a known amount of dried BSGs were added to the mixture and the reaction took place at the constant temperature. After a desired time, the reaction mixture was filtered under vacuum using Buchner funnel, giving meal and filtrate. Meal was washed with methanol to get the remaining products and this liquid was added to the filtrate. Methanol from the filtrate was evaporated by rotary evaporator, under vacuum, and the remaining liquid mixture was used to 
extract the products by liquid-liquid extraction using n-hexane as a solvent. Hexane richphase was then taken into a separate flask and the extraction was repeated three times using fresh n-hexane. Collected hexane-rich solution was evaporated in the rotary-evaporator and the remaining liquid was prepared for further Gas Chromatography (GC) analysis to determine the content of fatty acid methyl esters (FAMEs). All the transesterification reactions were performed in triplicate to allow the estimation of standard deviations.

Gas chromatography analysis of FAMEs were performed using Trace ${ }^{\mathrm{TM}}$ GC1300 with flame ionisation detector at $380^{\circ} \mathrm{C}$ and on-column injection with a $30 \mathrm{~m} \times 0.25 \mathrm{~mm}$ id capillary column (TR-BD(F), Thermo Scientific). Helium at $100 \mathrm{kPa}$ was used as a carrier gas. Oven temperature was $120{ }^{\circ} \mathrm{C}$ for $1 \mathrm{~min}$, followed by a $10{ }^{\circ} \mathrm{C} / \mathrm{min}$ ramp up to $220{ }^{\circ} \mathrm{C}$, with holding time of 10 min. Known standards of FAMEs (methyl palmitate, methyl linoleate, methyl linolenate and methyl oleate) were applied to identify the peaks while heptadecane was used as an internal standard. The data were processed with Chromeleon 7 software to obtain the peak areas and calculate yield of FAMEs. All the results present an average of at least two replicate analyses. 


\section{Results and Discussion}

\subsection{Drying}

Water content of brewers' spent grains was $(82.3 \pm 0.8)$ mass $\%$ which is within the reported range of 60 mass\% to 90 mass\% (Briggs et al., 2004). Drying kinetics under isothermal conditions were obtained by TGA at four temperatures $\left(60^{\circ} \mathrm{C}, 70^{\circ} \mathrm{C}, 80^{\circ} \mathrm{C}\right.$ and $\left.90^{\circ} \mathrm{C}\right)$ as shown in Figure 1. The moisture ratio was decreased with time which is enhanced by increasing temperature. Fick's second law for diffusion given by equation (5) was used to determine the diffusion coefficient $\left(D_{\text {eff }}\right)$, resulting in the following values $1.26 \times 10^{-9} \mathrm{~m}^{2} \mathrm{~s}^{-1}$, $1.42 \times 10^{-9} \mathrm{~m}^{2} \mathrm{~s}^{-1}, 2.14 \times 10^{-9} \mathrm{~m}^{2} \mathrm{~s}^{-1}$ and $2.67 \times 10^{-9} \mathrm{~m}^{2} \mathrm{~s}^{-1}$ at $60^{\circ} \mathrm{C}, 70^{\circ} \mathrm{C}, 80^{\circ} \mathrm{C}$ and $90^{\circ} \mathrm{C}$, respectively. As expected, the diffusion coefficient was enhanced by increasing temperature.

Diffusion coefficient expressed as $\ln \left(D_{\text {eff }}\right)$ as a function of $1 / T$ gave a straight line with slope of $-3200 \mathrm{~K}$. Activation energy was calculated according to equation (6) to be $26.6 \mathrm{~kJ} \mathrm{~mol}^{-1}$.

The obtained $D_{\text {eff }}$ and $E_{\text {a }}$ are comparable for reported values for the other agricultural wastes: olive-cake $-D_{\text {eff }}=1.71 \times 10^{-9}-2.03 \times 10^{-9} \mathrm{~m}^{2} \mathrm{~s}^{-1}$ from $50^{\circ} \mathrm{C}$ to $90^{\circ} \mathrm{C}, E_{\mathrm{a}}=12 \mathrm{~kJ} \mathrm{~mol}^{-1}(\mathrm{Vega}-$ Gálvez et al., 2010); corn $-D_{\text {eff }}=9.5 \times 10^{-9}-17.7 \times 10^{-9} \mathrm{~m}^{2} \mathrm{~s}^{-1}$ from $55^{\circ} \mathrm{C}$ to $70{ }^{\circ} \mathrm{C}, E_{\mathrm{a}}=29.6$ $\mathrm{kJmol}^{-1}$ (Doymaz and Pala, 2003); spent coffee grounds $-D_{\text {eff }}=1.3 \times 10^{-9}-6 \times 10^{-9} \mathrm{~m}^{2} \mathrm{~s}^{-1}$ from $100^{\circ} \mathrm{C}$ to $250^{\circ} \mathrm{C}, E_{\mathrm{a}}=12 \mathrm{~kJ} \mathrm{~mol}^{-1}$ (Gómez-de la Cruz at al. 2015)

Drying rates as function of time at four studied temperatures are presented in Figure 2, showing different drying mechanisms at different temperatures. Three drying phases were observed at $\left.60^{\circ} \mathrm{C}: \mathrm{i}\right)$ initial period when the drying rate sharply increases, which is associated with heating up of the material, ii) the constant rate periods, representing evaporation of water from the saturated surface of the material, and iii) the failing period when water migrates from the inner structure to the surface. 
At higher temperatures of $70^{\circ} \mathrm{C}$ and $80^{\circ} \mathrm{C}$, the constant rate period disappeared and the failing period of drying rate was observed soon after the initial increasing rate period. Also, there are two falling rate periods: 1) the first failing period during which the surface of the material has both longer saturated and dry spots and mass transfer is controlled by both diffusion and evaporation; and, 2) second failing period when the surface of material is completely dry and the water diffuses through the solid.

At the highest experimental temperature $\left(90^{\circ} \mathrm{C}\right)$, only the initial and one failing periods were observed, meaning that most of water present at surface of material evaporates during the initial heating up period, followed by the diffusion from inner solid structure.

Four different models were used to fit experimental drying curve presented in Figure 1, namely Page, Newton, Midilli-Kucuk and Logaritmic (given in Table 1). Obtained models' parameters are given in Table 1 along with the linear correlation coefficient $\left(r^{2}\right)$ and standard deviation $(S D)$. It can be concluded that all the models presented reasonably good fit, but the best results were achieved by Midilli-Kucuk model, which is not surprising since it comprises the highest number of parameters.

\subsection{In situ transesterification}

The oil yield obtained by Soxhlet extraction using solvent as $(7.5 \pm 0.1)$ mass $\%$ g per g of dry SCGs which is in good agreement with the oil content in BSGs reported in literature, ranging from 3.9 mass $\%$ to 13.3 mass \%, as summarized in Table 2. The extracted BSGs' oil was titrated by sodium hydroxide in order to determine its fatty acid content. The acid value was $(32.6 \pm 0.1) \mathrm{mg} \mathrm{KOH}$ per $\mathrm{g}$ of oil which corresponds to a very high content of free fatty acids (approximately 16.3 mass\%), and therefore acidic catalyst was chosen for in situ transesterification process. 
Influences of four important reaction parameters on the yield of in situ transesterification reaction were studied in this work. The reaction yield was initially increased with time from $55.5 \%$ after 120 minutes to $72.6 \%$ after 300 minutes (Fig.5) but the yield remained the same after longer periods of time. The reaction yields were also enhanced by increasing methanol to BSGs ratio, reaching maximum for $7.7 \mathrm{~mL} / \mathrm{g}$. However, decrease in the yield was observed with further increase of the ratio (Fig.6). This trend is well documented to other in situ transesterification, such as that from the spent coffee grounds (Najdanovic-Visak et al., 2017) and from Jatropha curcas (Kasim and Harvey, 2011). Initial yield increase is due to higher concentration of methanol favouring the biodiesel production while further increase in amount of methanol dilutes triglycerides leading to lower reaction rates.

As it can be observed from Fig.7, the reaction yield was initially enhanced with increased catalyst concentrations and then declined, which might be due to the reversible nature of the transesterification process. Higher concentrations of the catalyst may have favoured the backward reaction - the formation of triglycerides. Finally, we performed in situ transesterification at different temperature (Fig.8). The yield increased from $59.7 \%$ at $36^{\circ} \mathrm{C}$ to $83.3 \%$ at $60^{\circ} \mathrm{C}$.

\section{Conclusions}

We reveal the drying kinetics of brewers' spent grains and that it is feasible to perform in situ transesterification of oils from brewers' spent grains for the biodiesel production. At lower temperature, three stages of the drying process were observed: initial heating up, constant drying rate period and failing drying rate period. At higher temperature, only initial heating up and failing drying rate period were observed. 
Our findings reveal that triglycerides present in BSGs can be converted to biodiesel in a single step using $\mathrm{H}_{2} \mathrm{SO}_{4}$ as catalyst. The maximum achieved yield of in situ transesterification was $83.3 \%$ achieved. 


\section{References:}

The Brewers of Europe: "The contribution made by beer to European economy" (2016), [online] http://www.brewersofeurope.org/uploads/mycmsfiles/documents/publications/2016/EU_economic_report_2016_web.pdf, accessed 18-Dec2017.

Briggs, D.E, Brookes, P.A, Stevens, R., Boulton, C.A., 2004. Brewing: Science and practice. Boca Raton, FL: CRC Press [u.a.]

Chen, D., Zheng, Y., Zhu, X., 2012. Determination of effective moisture diffusivity and drying kinetics for poplar sawdust by thermogravimetric analysis under isothermal condition. Bioresour. Technol. 107, 451-455.

Doymaz, I., Pala, M., 2003. The thin-layer drying characteristics of corn. J. Food Eng. 60, 125-130.

Ertekin, C., Firat, M.Z., 2017. A comprehensive review of thin-layer drying models used in agricultural products. Crit. Rev. Food Sci. Nutr. 57, 701-717.

Gómez-de la Cruz, F.J., Cruz-Peragón, F., Casanova-Peláez, P.J., Palomar-Carnicero, J.M., 2015. A vital stage in the large-scale production of biofuels from spent coffee grounds: The drying kinetics. Fuel Sci. Technol. 130, 188-196.

Haas, M.J., Scott, K.M., Marmer, W.N., Foglia, T.A., 2004. In situ alkaline transesterification: An effective method for the production of fatty acid esters from vegetable oils. J. Am. Oil Chem. Soc. 81, 83-89.

Haas, M.J., Wagner, K., 2011. Simplifying biodiesel production: the direct or in situ transesterification of algal biomass. Eur. J. Lipid Sci. Technol. 113, 1219-1229.

Kanauchi, O., Mitsuyama, K., Araki, Y., 2001. Development of a functional germinated barley foodstuff from brewer's spent grain for the treatment of ulcerative colitis. J. Am. Soc. Brew. Chem. 59, 59-62.

Kasim, F.H., Harvey, A.P., 2011. Influence of various parameters on reactive extraction of Jatropha curcas L. for biodiesel production. Chem. Eng. J. 171, 1373-1378.

Kim, B., Im, H., Lee, J.W., 2015. In situ transesterification of highly wet microalgae using hydrochloric acid. Bioresour. Technol. 185, 421-425.

Liang, S., Wan, C., 2015. Carboxylic acid production from brewer's spent grain via mixed culture fermentation, Bioresour. Technol. 182, 179-183.

Lynch, K.M., Steffen, E.J., Arendt, E.K., 2016. Brewers' spent grain: a review with an emphasis on food and health, Journal of the Institute of Brewing 122, 553-568. 
Mussatto, S.I., Moncada, J., Roberto, I.C., Cardona, C.A., 2013. Techno-economic analysis for brewer's spent grains use on a biorefinery concept: The Brazilian case, Bioresour. Technol. 148, 302-310.

Najdanovic-Visak, V., Lee, F. Y.-L., Tavares, M.T., Armstrong, A. 2017, Kinetics of extraction and in situ transesterification of oils from spent coffee grounds, J. Environ. Chem. Eng. 5, 2611-2616.

O'Brien, N., FitzGerald, R., Piggott, C., O'Callaghan, Y. and McCarthy, A., 2012. Brewers' spent grain; bioactivity of phenolic component, its role in animal nutrition and potential for incorporation in functional foods: A review. Proc. Nutr. Soc. 72, 117-125.

Plaza, P.E., Gallego-Morales, L.J., Peñuela-Vásquez, M., Lucas, S., García-Cubero, M.T., Coca, M., 2017. Biobutanol production from brewer's spent grain hydrolysates by Clostridium beijerinckii, Bioresour. Technol. 244, 166-174.

Qian, J., Yang, Q., Sun, F., He, M, Chen, Q., Yun, Z., Qin, L., 2013. Cogeneration of biodiesel and nontoxic rapeseed meal from rapeseed through in-situ alkaline transesterification. Bioresour. Technol. 128, 8-13.

Rehan, M., Gardy, J., Demirbas, A., Rashidd, U., Budzianowski, W.M., Pant, D., Nizami, A.S., 2017. Waste to Biodiesel: A Preliminary Assessment for Saudi Arabia. Bioresour. Technol., In press.

Roberto, I., Dragone, G., Mussatto, S., 2006. Brewers' spent grain: Generation, characteristics and potential applications. J. Cereal. Sci. 43, 1-14.

del Río, J.C., Prinsen, P., Gutiérrez, A., 2013. Chemical composition of lipids in brewer's spent grain: A promising source of valuable phytochemicals. J. Cereal Sci. 58, 248-254.

Santos, M., Jiménez, J.J., Bartolomé, B., Gómez-Cordovés, C., del Nozal, M.J, 2003. Variability of brewer's spent grain within a brewery. Food Chem. 80, 17-21.

Sinha, P., Islam, M.A., Negi, M.S., Tripathi, S.B., 2015. Changes in oil content and fatty acid composition in Jatropha curcas during seed development. Ind. Crops Prod. 77, 508-510.

Statista, 2017. Beer production worldwide from 1998 to 2016. Statistics portal, online: https://www.statista.com/statistics/270275/worldwide-beer-production/, accessed on 18-Dec2017.

Thomas, K.R., Rahman, P.K.S.M., 2006. Brewery wastes. Strategies for sustainability. A review. Aspects of Applied Biology 80, 147-153.

Vega-Gálvez, A., Miranda, M., Díaz, L.P., Lopez, L., Rodriguez, K., Scala, K.D., 2010. Effective moisture diffusivity determination and mathematical modelling of the drying curves of the olive-waste cake. Bioresour. Technol. 101, 7265-7270. 
Watson, B. 2016, Economic impact, the Brewers Association, [online]

https://www.brewersassociation.org/statistics/economic-impact-data/, accessed 18-Dec-2017.

Xiros, C., Topakas, E., Katapodis, P., Christakopoulos, P., 2008. Hydrolysis and fermentation of brewer's spent grain by Neurospora crassa. Bioresour. Technol. 99, 5427-5435.

Yang, H., Yan, R., Chin, T., Liang, D.T., Chen, H. Zheng, C., 2004. Thermogravimetric Analysis-Fourier Transform Infrared Analysis of Palm Oil Waste Pyrolysis. Energy Fuels $18,1814-1821$.

Zhang, J., Zang, L. 2016, Enhancement of biohydrogen production from brewers' spent grain by calcined-red mud pretreatment. Bioresour. Technol. 209, 73-79. 


\section{Figure Captions}

Figure 1. Drying curve - moisture ratio versus time for brewers' spent grains at various isothermal conditions in TGA apparatus: circle $-60^{\circ} \mathrm{C}$, square $-70^{\circ} \mathrm{C}$, triangle $-80^{\circ} \mathrm{C}$ and cross $-90^{\circ} \mathrm{C}$.

Figure 2. Drying rate versus time for brewers' spent grains at various isothermal conditions in TGA apparatus: solid line $-60^{\circ} \mathrm{C}$, short-dashed line $-70^{\circ} \mathrm{C}$, long-dashed line $-80^{\circ} \mathrm{C}$ and dash-dotted line $-90^{\circ} \mathrm{C}$.

Figure 3. Yield of in situ transesterification of oils from BSGs as a function of time. Reaction

conditions: $60^{\circ} \mathrm{C}$, methanol to BSGs $5.6 \mathrm{~mL} / \mathrm{g}$, catalyst concentration $C_{\mathrm{H} 2 \mathrm{SO} 4}=1.54 \mathrm{~mol} \mathrm{dm}^{-3}$

Figure 4. Yield of in situ transesterification of oils from BSGs as a function of methanol to BSGs ratio. Reaction conditions: $60^{\circ} \mathrm{C}$, time $=300 \mathrm{~min}$, catalyst concentration

$$
C_{\mathrm{H} 2 \mathrm{SO} 4}=1.54 \mathrm{~mol} \mathrm{dm}^{-3} \text {. }
$$

Figure 5. Yield of in situ transesterification of oils from BSGs as a function of catalyst concentration $\left(C_{\mathrm{H} 2 \mathrm{SO} 4}\right)$. Reaction conditions: $60^{\circ} \mathrm{C}$, time $=300 \mathrm{~min}$, methanol to BSGs 7.2 $\mathrm{mL} / \mathrm{g}$.

Figure 6. Yield of in situ transesterification of oils from BSGs as a function of temperature. Reaction conditions: time $=300 \mathrm{~min}$, methanol to BSGs $7.2 \mathrm{~mL} / \mathrm{g}$, catalyst concentration $C_{\mathrm{H} 2 \mathrm{SO} 4}=0.95 \mathrm{~mol} \mathrm{dm}^{-3}$. 
Table 1. Parameters of drying models

\begin{tabular}{|c|c|c|c|c|c|c|c|c|}
\hline \multirow{2}{*}{ Model } & \multirow{2}{*}{ Equation } & \multirow{2}{*}{$T /{ }^{\circ} \mathrm{C}$} & \multicolumn{4}{|c|}{ model parameters } & \multirow[b]{2}{*}{$r^{2}$} & \multirow[b]{2}{*}{$S D$} \\
\hline & & & $a$ & $b$ & $k$ & $n$ & & \\
\hline \multirow{4}{*}{ Page } & \multirow{4}{*}{$M R=\exp \left(-k t^{n}\right)$} & 60 & & & $(2.48 \pm 0.25) \cdot 10^{-5}$ & $1.492 \pm 0.014$ & 0.9947 & 0.023 \\
\hline & & 70 & & & $(5.22 \pm 0.34) \cdot 10^{-5}$ & $1.495 \pm 0.010$ & 0.9981 & 0.012 \\
\hline & & 80 & & & $(6.64 \pm 0.47) \cdot 10^{-5}$ & $1.494 \pm 0.011$ & 0.9977 & 0.013 \\
\hline & & 90 & & & $(10.1 \pm 0.66) \cdot 10^{-5}$ & $1.493 \pm 0.011$ & 0.9980 & 0.011 \\
\hline \multirow{4}{*}{ Newton } & \multirow{4}{*}{$M R=\exp (-k t)$} & 60 & & & $(8.77 \pm 0.14) \cdot 10^{-4}$ & & 0.9546 & 0.067 \\
\hline & & 70 & & & $(14.7 \pm 0.22) \cdot 10^{-4}$ & & 0.9670 & 0.051 \\
\hline & & 80 & & & $(17.2 \pm 0.26) \cdot 10^{-4}$ & & 0.9682 & 0.047 \\
\hline & & 90 & & & $(22.7 \pm 0.34) \cdot 10^{-4}$ & & 0.9708 & 0.041 \\
\hline \multirow{4}{*}{$\begin{array}{l}\text { Midilli- } \\
\text { Kucuk }\end{array}$} & \multirow{4}{*}{$M R=a \exp \left(-k t^{n}\right)+b t$} & 60 & $0.955 \pm 0.005$ & $(-6.18 \pm 0.76) \cdot 10^{-6}$ & $(1.41 \pm 0.20) \cdot 10^{-5}$ & $1.560 \pm 0.019$ & 0.9972 & 0.017 \\
\hline & & 70 & $0.956 \pm 0.003$ & $(-3.71 \pm 2.69) \cdot 10^{-7}$ & $(2.30 \pm 0.19) \cdot 10^{-5}$ & $1.610 \pm 0.012$ & 0.9990 & 0.009 \\
\hline & & 80 & $0.952 \pm 0.003$ & $(-2.45 \pm 2.81) \cdot 10^{-7}$ & $(2.70 \pm 0.25) \cdot 10^{-5}$ & $1.623 \pm 0.014$ & 0.9987 & 0.010 \\
\hline & & 90 & $0.951 \pm 0.003$ & $(-1.51 \pm 2.20) \cdot 10^{-7}$ & $(4.19 \pm 0.34) \cdot 10^{-5}$ & $1.63 \pm 0.013$ & 0.9989 & 0.008 \\
\hline \multirow{4}{*}{ Logaritmic } & \multirow{4}{*}{$M R=a+b \exp (-k t)$} & 60 & $\begin{array}{l}-0.1335 \pm \\
0.0090 \\
-0.0287 \pm\end{array}$ & $1.2157 \pm 0.0086$ & $(7.2188 \pm 0.161) \cdot 10^{-4}$ & & 0.9888 & 0.034 \\
\hline & & 70 & $\begin{array}{l}0.0038 \\
-0.0211 \pm\end{array}$ & $1.1539 \pm 0.0106$ & $(1.518 \pm 0.0274) \cdot 10^{-3}$ & & 0.9836 & 0.036 \\
\hline & & 80 & $\begin{array}{l}0.0033 \\
-0.0128 \pm\end{array}$ & $1.1489 \pm 0.0112$ & $(1.81 \pm 0.0324) \cdot 10^{-3}$ & & 0.9828 & 0.035 \\
\hline & & 90 & 0.0026 & $1.1417 \pm 0.0116$ & $(2.45 \pm 0.04186) \cdot 10^{-3}$ & & 0.9828 & 0.031 \\
\hline
\end{tabular}


Table 2. Oil content in brewers' spent grains from different studies

\begin{tabular}{cl}
\hline Oil content (mass\% dry bases) & Source \\
\hline 7.5 & This work \\
3.9 & Santos et al., 2003 \\
9.2 & Río et al., 2013 \\
13.3 & Xiros et al., 2008 \\
10.6 & Kanauchi et al., 2001 \\
\hline
\end{tabular}


Figure 1

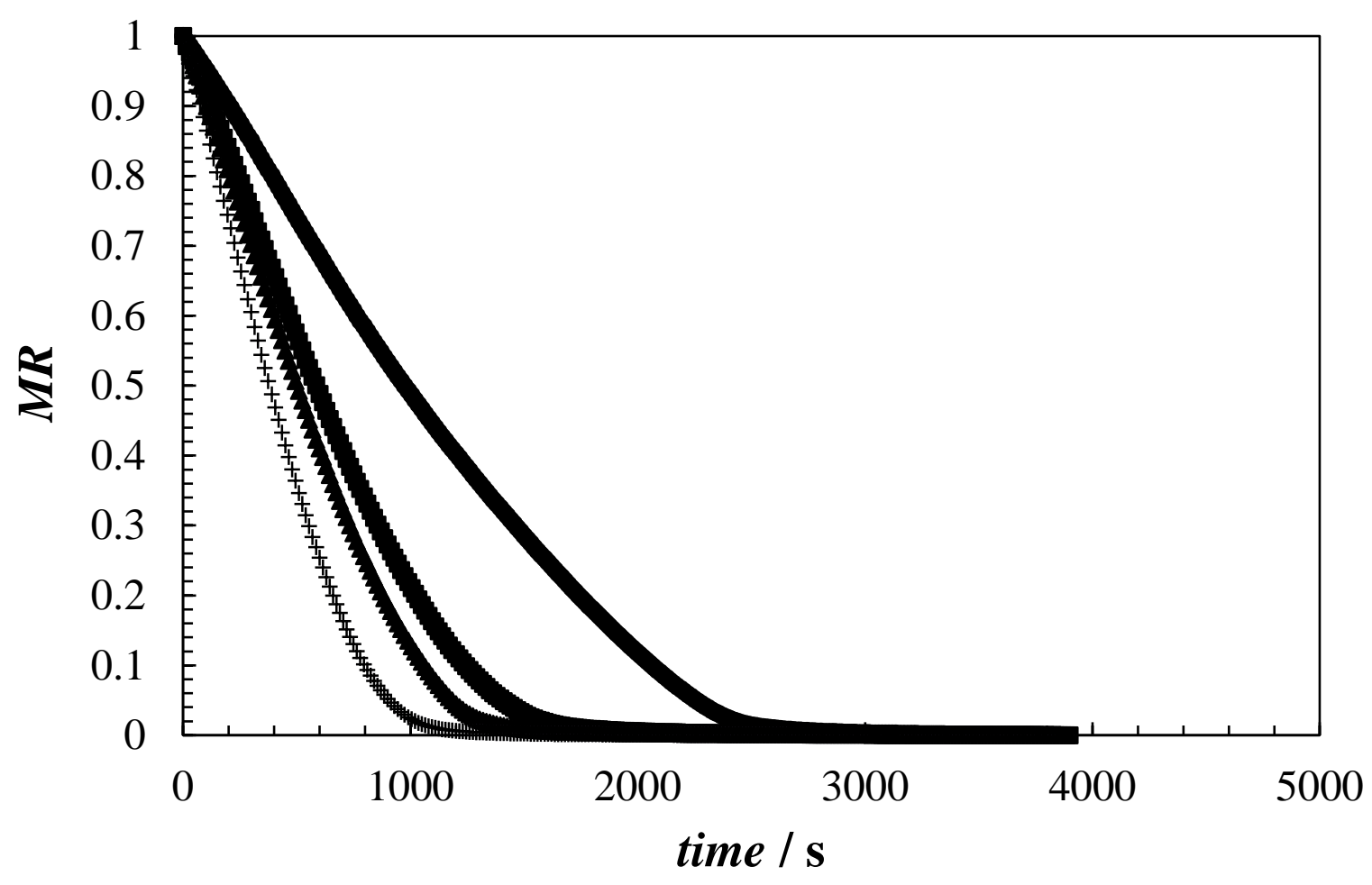


Figure 2

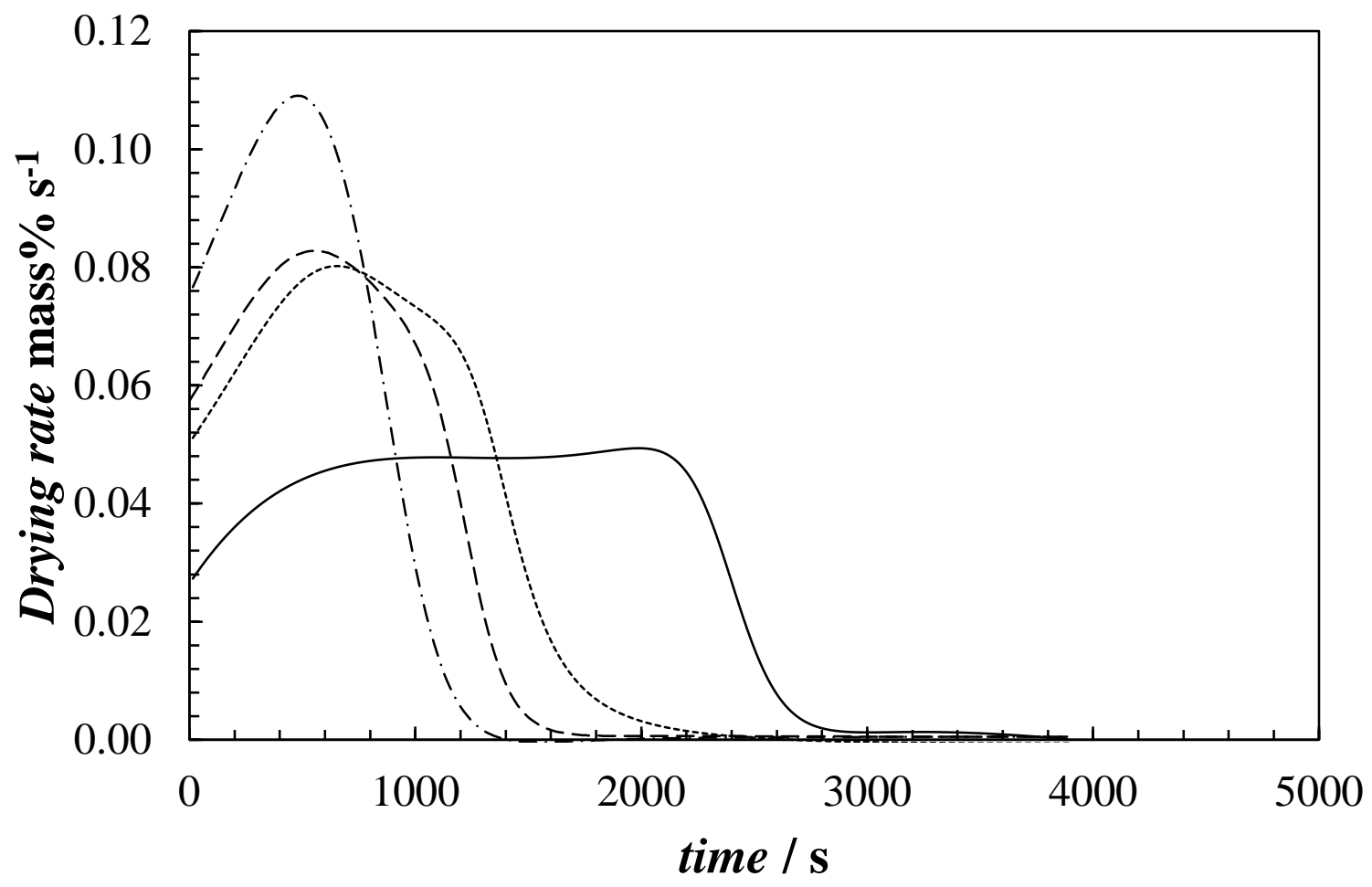


Figure 3

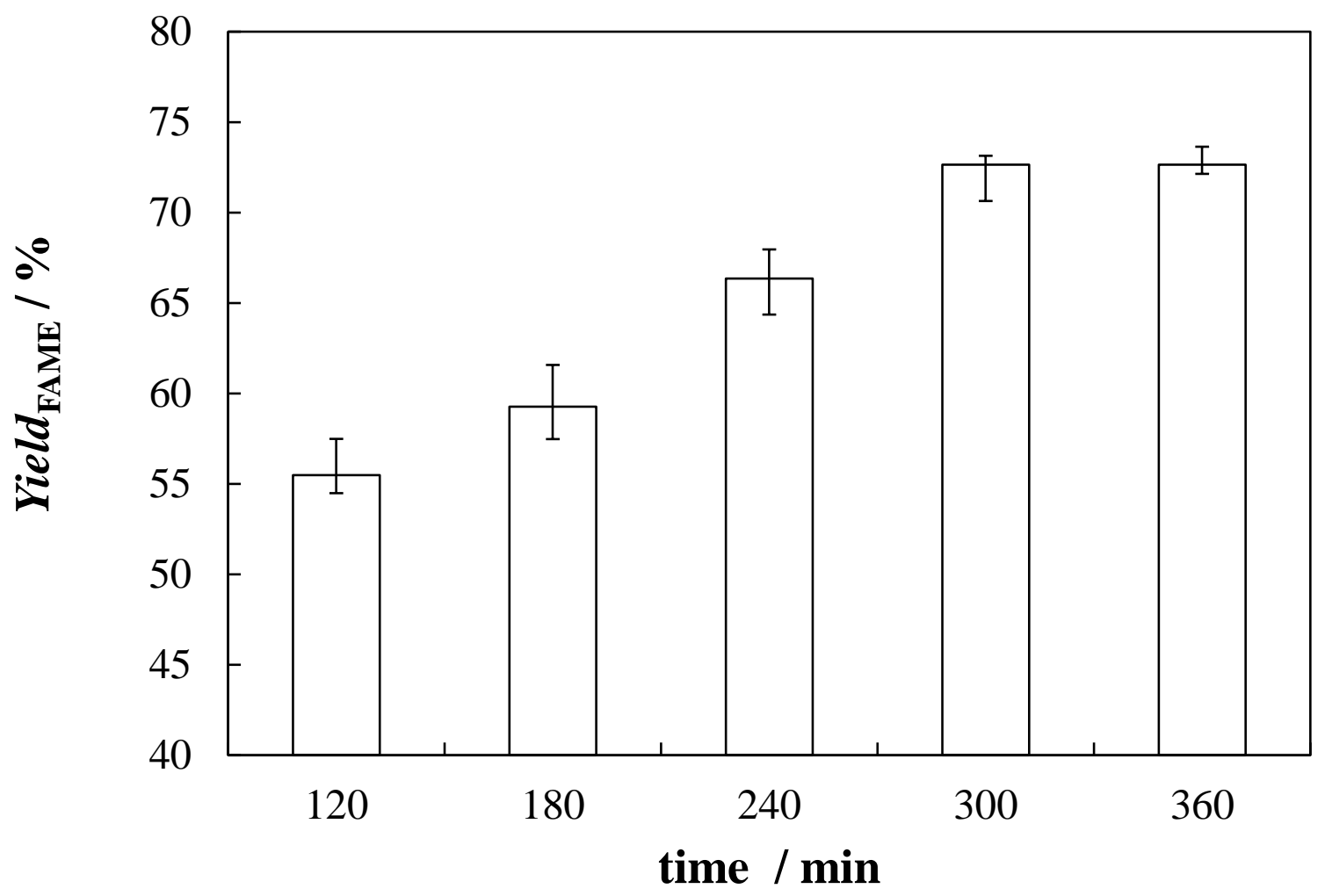


Figure 4

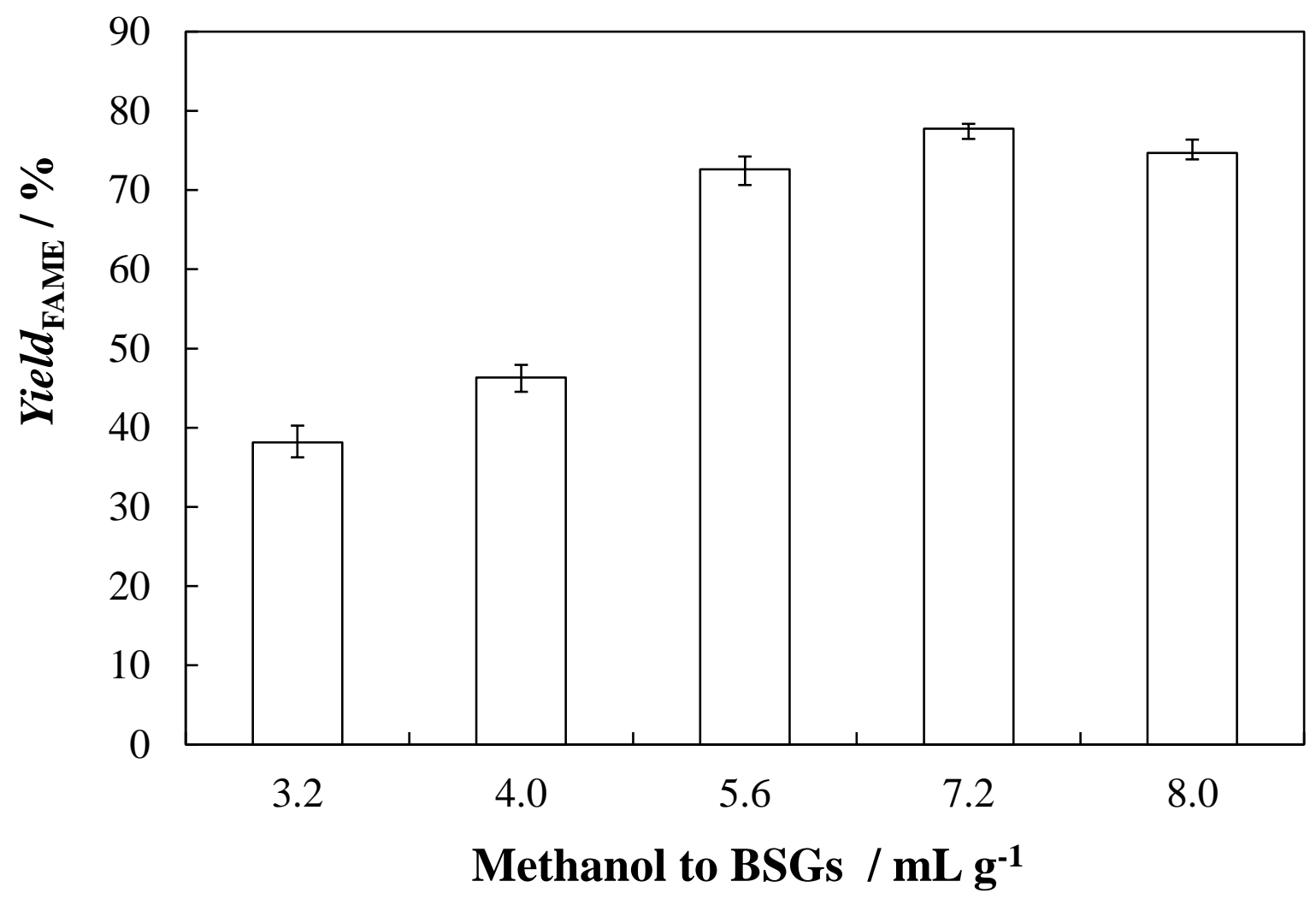


Figure 5

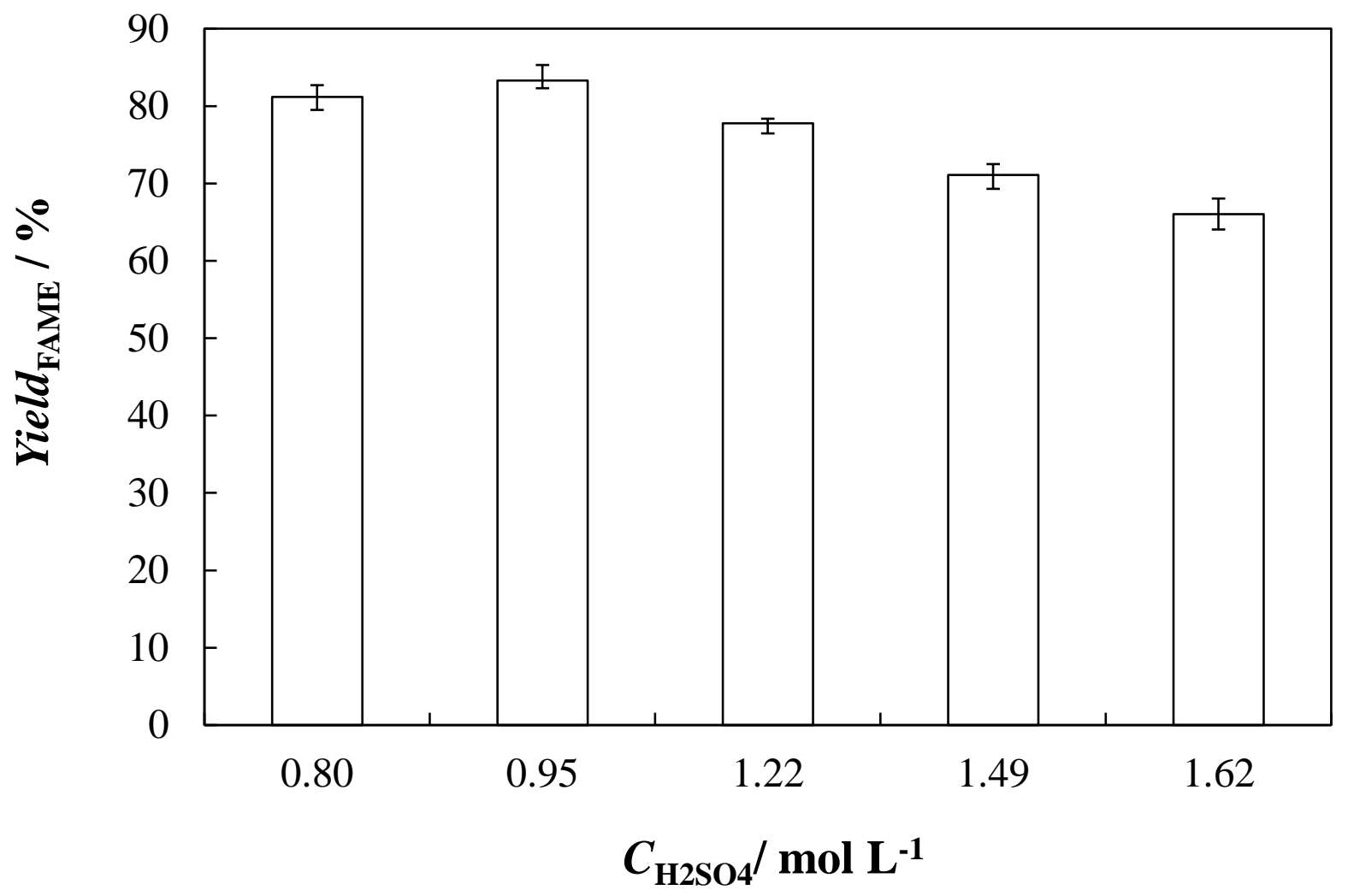


Figure 6

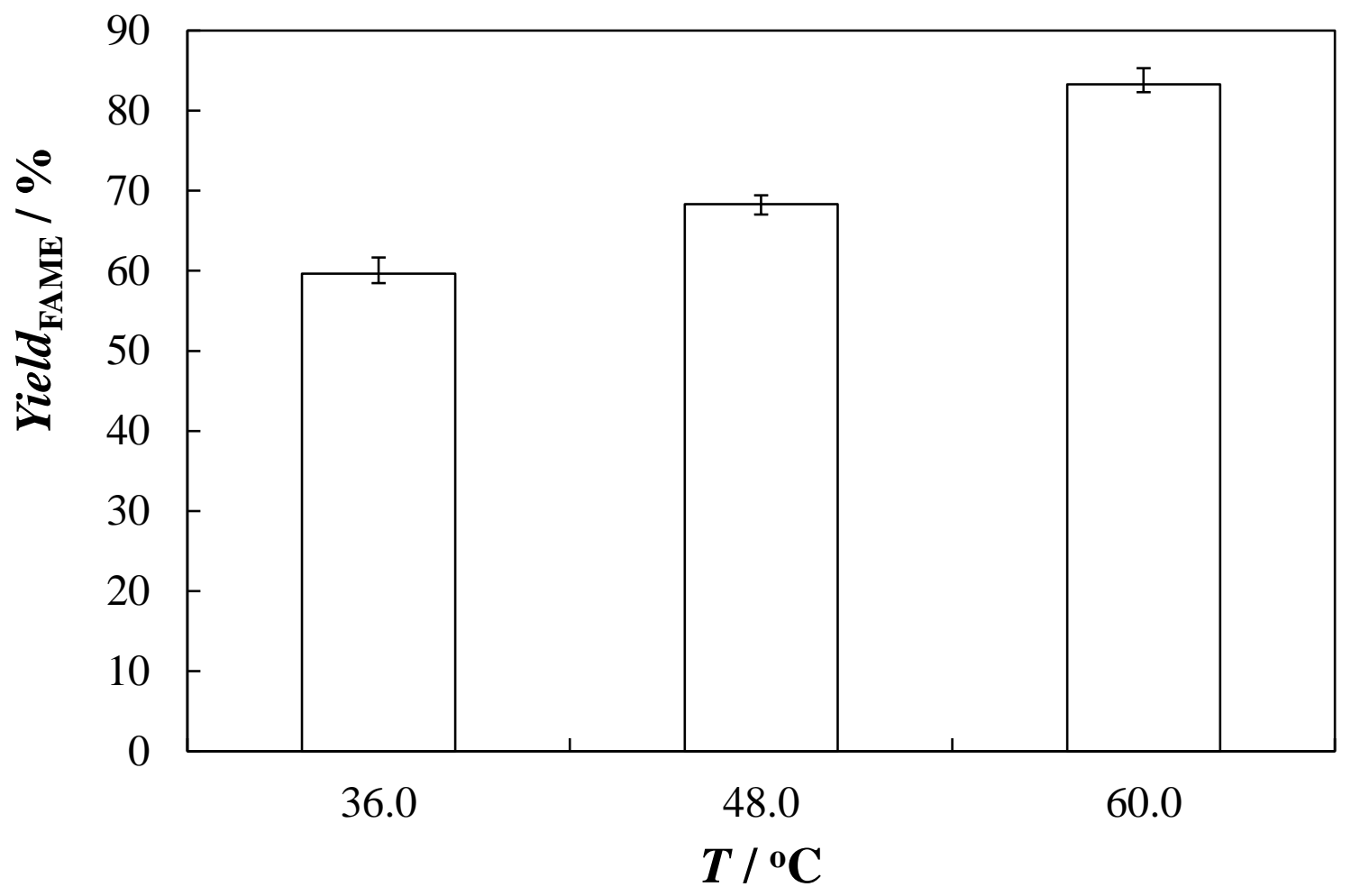


